\title{
O ANO DE 1968 EM CUBA: MUDANÇAS NA POLÍTICA INTERNACIONAL E NA POLÍTICA CULTURAL
}

\author{
Sílvia Cezar Miskulin* \\ Pós-Doutoranda em História na USP \\ silmiskulin@uol.com.br
}

\begin{abstract}
Resumo:O artigo analisa os principais acontecimentos ocorridos em Cuba durante o ano de 1968 e enfatiza as mudanças na política externa, após o apoio do governo cubano à invasão da Checoslováquia pela União Soviética, para acabar com a Primavera de Praga. O artigo buscou compreender também as polêmicas premiações dos concursos literários deste ano e os conflitos entre os intelectuais e o governo, com o fechamento da política cultural oficial e a delimitação da liberdade de expressão e criação em Cuba.
\end{abstract}

Palavras-chave: Cuba; Cultura; Política; Revolução.

\section{The year of 1968 in Cuba: changes in international politics and in cultural politics}

\begin{abstract}
The article analyzes the main events happened in Cuba during the year of 1968 and emphasizes the changes in the external politics, after the support of Cuban government at the Thecoslováquia invasion by the Soviet Union, to end the Praga's Spring. The paper sought to understand the controversial prizes of the literatures competitions in this year and the conflicts among the intellectuals and government representatives, considering the assumed by the official cultural policies and the utterance and artistic freedom limitations in Cuba.
\end{abstract}

Key Words: Cuba; Culture; Politics; Revolution.

Ao iniciar o ano de 1968, a atração internacional que a Revolução Cubana exercia entre os intelectuais de esquerda e a juventude de vários países do mundo era enorme. Che Guevara em seu projeto de expandir a revolução por meio da guerrilha, acabava de ser assassinado em outubro de 1967, pelas forças de repressão na Bolívia. Suas idéias faziam parte do imaginário da juventude, sobretudo no que

\footnotetext{
* Este artigo é um desdobramento da Tese de Doutorado Os intelectuais cubanos e a política cultural da Revolução (196 I-1975), que se encontra no prelo e será publicada pela editora Alameda com o auxílio da FAPESP.
} 
diz respeito à exaltação da figura de Che Guevara como o grande 'guerrilheiro heróico', que morreu pela causa revolucionária, além da defesa sistemática de um pensamento e prática antiimperialista e "terceiro-mundista". Não por acaso o ano de 1968 em Cuba foi batizado como o "ano do guerrilheiro heróico".

CheGuevaranãoeraaúnica personalidade emblemáticanoimagináriopolítico da "geração dos anos 68", mas figuras como Fidel Castro, Hô Chi Minh e Mao Zé Dong também eram símbolos internacionalmente difundidos, como nos revelou o estudo de Robert Frank ${ }^{1}$. Na sua visão, os movimentos de contestação de juventude da América e da Europa se reconheciam nestas personalidades emblemáticas e míticas, que encarnavam a resistência ao imperialismo estadunidense e haviam travado sua luta em países da América Latina e da Ásia. Estas figuras representavam uma alternativa ao projeto da União Soviética e contestavam o modelo soviético como forma de transformação social. Com a morte de Che Guevara, sua imagem foi reproduzida ao máximo e levada em inúmeras manifestações ao longo de 1968 e até os dias de hoje.

O símbolo de Che Guevara e de outros líderes do Terceiro Mundo criavam um novo modelo de ativismo no cenário mundial ${ }^{2}$, cuja filosofia de ação baseavase na revolução permanente, nos questionamentos "anti-autoritários", na "audácia e imaginação no poder.” Estas idéias estiveram presentes na revolução cultural da China $^{3}$ e nos protestos da juventude que eclodiram em 1968, seja em maio na França, ou nos Estados Unidos contra a guerra do Vietnã, ou ainda nas manifestações do México, Brasil, Alemanha, Checoslováquia, entre outros países.

A prova desta simpatia mundial pela Revolução Cubana foi o êxito do Congresso Cultural de Havana, realizado entre 4 a 12 de janeiro de 1968, que reuniu cerca de quinhentos intelectuais de setenta países. O apoio a Cuba ficou explícito com a reunião de inúmeros escritores e artistas que viam na ilha uma nova alternativa de transformação social, que fugia dos métodos repressivos utilizados na União Soviética e no Leste Europeu. O livro organizado por Mario Benedetti compilou diversas comunicações apresentadas nesse Congresso por Ambrosio Fornet, Jorge Enrique Adoun, Santiago Alvarez, Roger Smith, Irving Teitbaum, Catherine Varlin, Jesús Díaz, Juan Valdés-Paz, Rossana Rossanda, Adolfo Sánchez Vázquez, Mohamed Rawash El-Diab e Graciela Pogolotti, além das saudações de Ernest Fischer e Jean-Paul Sartre, que não puderam comparecer por motivos de saúde ${ }^{4}$.

O Congresso Cultural de Havana tinha como objetivo reforçar o engajamento político de escritores e artistas e fortalecer a concepção das produções culturais como parte da luta antiimperialista, em prol das revoluções e do "Terceiro Mundo". No âmbito cultural, o Congresso deliberou pela recusa dos "vanguardismos" nas manifestações artísticas, já que as obras experimentais não eram acessíveis à maioria 
da população. Buscou-se a popularização da cultura, por meio da ampliação dos colaboradores e dos jovens no meio cultural cubano, priorizando a informação e a práxis, e deixando de lado as reflexões teóricas e formais ${ }^{5}$. O Congresso deliberou sobre a necessidade da "luta armada" e da participação dos intelectuais para se alcançar as transformações nos "países subdesenvolvidos". Muitos intelectuais declararam em Havana sua disposição de apoiar a luta armada nos países subdesenvolvidos e inclusive de morrer, caso fosse preciso, para a construção de uma nova sociedade. O Congresso votou ainda em suas resoluções finais que a guerra popular e a luta armada eram "das manifestações mais elevadas da cultura" e a necessidade e compromisso dos intelectuais se engajarem e participarem das lutas revolucionárias no "Terceiro Mundo".

Fidel Castro realizou o discurso de encerramento do evento, em que declarou como o Congresso era "um Vietnã no campo da cultura" e frisou o importante papel dos intelectuais como vanguarda na compreensão dos problemas contemporâneos e na condução das revoluções no "Terceiro Mundo". Ficava claro o apoio de Cuba à luta do povo no Vietnã e aos movimentos guerrilheiros, como já havia sido elaborado com a realização um ano antes da Primeira Conferência da Organización Latinoamericana de Solidariedad (OLAS) ${ }^{8}$. Entretanto, o Congresso Cultural de Havana não abriu espaços para grandes polêmicas. Os temas que exigiam maiores debates foram previamente selecionados e evitados no Congresso, já que o governo cubano não queria que surgissem impasses ou divergências diante da presença de convidados estrangeiros. Justamente para atingir essa finalidade, o governo realizou o Seminário Preparatório do Congresso Cultural de Havana, entre 25 de outubro a 2 de novembro de 1967, com a participação de mais de mil escritores, artistas e intelectuais cubanos, reunidos em diversas comissões culturais. O Seminário era aparentemente para organizar o Congresso, mas foi um espaço de "patrulhamento ideológico" entre os distintos grupos da intelectualidade da ilha9. Durante este Seminário, o governo deixou claro certas restrições aos intelectuais como a eliminação do direito autoral, além de proibir a utilização do conceito "trabalhador intelectual", que criava uma diferenciação indesejada com o "trabalhador braçal".

A política oficial cubana foi dura ao reprimir os intelectuais negros nas vésperas do Congresso Cultural de Havana. Alguns dias antes do início do evento, o ministro da Educação José Llanusa Gobels convocou para uma reunião no Hotel Habana Libre os intelectuais negros considerados "problemáticos": o historiador, etnólogo e diplomata Walterio Carbonell, o etnólogo e poeta Rogelio Martínez Furé, a poeta Nancy Morejón, os cineastas Nicolás Guillén Landrián e Sara Gómez, os etnólogos Pedro Deschamps Chapeaux e Alberto Pedro, os escritores e jornalistas Juan Manuel Casanova e Luis M. Saenz, os dramaturgos Eugenio Hernández e Gerardo Fulleda León, os escritores Ana Justina, Serafín Quiñones, Manuel Granados, Wichy el negro, Pedro Peréz Sarduy e Esteban Cárdenas. 
Nesta reunião o ministro José Llanusa teria primeiramente dito que havia um interesse do governo em discutir a questão dos negros e exortou os participantes a se expressarem livremente, segundo Carlos Moore ${ }^{10}$. Mas, ao final da discussão, Llanusa os acusou de sedição e declarou que a Revolução não iria tolerar atividades que "dividissem o povo cubano" em termos étnicos. O ministro declarou também que apenas o governo e o partido estavam autorizados a teorizar no campo da cultura e somente "inimigos da Revolução" poderiam falar de um assunto que já estava resolvido desde o triunfo da Revolução. Os intelectuais foram acusados de planejar um complô, por fazerem reuniões privadas para redigir um "manifesto negro", sobre o problema de etnia e cultura em Cuba, que seria apresentado no Congresso. Assim como ocorria nesses anos nos Estados Unidos um forte movimento negro que reivindicava ampliação dos direitos dos afro-descendentes na sociedade estadunidense, em Cuba este debate era tolhido pelo governo com a justificativa de que a Revolução Cubana havia resolvido o problema dos negros na ilha. Os intelectuais foram silenciados e reprimidos de distintas maneiras. Ficaram proibidos de comparecer ao Congresso Cultural de Havana, muitos foram mantidos confinados em suas casas e Walterio Carbonell, Wichy "el negro" e Nicolas Guillén Landrián foram imediatamente presos. O livro de Carbonell, Como surgió la cultura nacional, já havia sido proibido em 1961, e seu autor foi preso em 1968 em um campo em Camagüey. Devido às pressões, Manuel Granados tentou aparentemente se suicidar e foi internado em hospital psiquiátrico. O cineasta Nicolas Guillén Landrián teve problemas mentais na prisão e foi transferido para um hospital psiquiátrico. Já a cineasta Sara Gómez acabou se suicidando nos anos setenta. Como mostrou Mariana Martins Villaça em sua análise sobre o cinema cubano, esses cineastas já haviam mostrado em seus documentários o problema da marginalização dos negros e foram alvo de fortes críticas, além da diminuição do tempo em cartaz dos filmes ${ }^{11}$. O único representante negro na delegação cubana do Congresso foi o presidente da Unión Nacional de Escritores y Artistas Cubanos (Uneac), o poeta Nicolas Guillén, que não fazia parte do grupo.

O fascínio internacional que Cuba exercia perante a esquerda mundial não durou muito tempo ${ }^{12}$. As manifestações internacionais ao longo de 1968 marcaram significativamente os acontecimentos em Cuba, sobretudo a Primavera de Praga, conforme relatou o escritor Pío Serrano, que nesses anos era estudante em Cuba:

Por otra parte, la irrupción de los tanques soviéticos en Praga ponía fin a una experiencia de socialismo con rostro humano, que desde La Habana era seguida con enorme interés e ilusión. En un primer momento Castro, que por entonces hacía sus últimas visitas imprevistas a la Universidad, declaró ante los estudiantes universitarios en la Plaza Cárdenas su condena a la invasión de Praga. Sin embargo, dos días 
después, en una súbita comparecencia televisiva justificaba el aplastamiento de un modelo de socialismo visto con simpatía por la mayoría de nosotros. Era, sin duda, la expresión conforme a la exigencia de la férrea mano de Brejnev que no estaba dispuesto a tolerar nuevas veleidades al indócil socialismo criollo. ${ }^{13}$

A Primavera de Praga, movimento que reivindicou "um socialismo com rosto mais humano", foi duramente reprimido pelos tanques da União Soviética, em 21 de agosto de 1968. Nos primeiros dias da repressão, a imprensa cubana noticiou o episódio, solidarizando-se com os manifestantes em Praga, já que havia uma simpatia na ilha com relação ao movimento checo. O discurso de Fidel Castro em 23 de agosto acabou por definir a posição oficial do governo cubano e seu apoio à invasão soviética a Praga surpreendeu não só muitos cubanos, como também grande parte da intelectualidade de esquerda internacional, que era simpática a Cuba e à "nova esquerda"14.

O apoio do governo cubano à repressão soviética, esmagando o movimento de aspirações democráticas da Primavera de Praga foi um marco na política externa cubana. A justificativa de Fidel era que a União Soviética tratava de defender o socialismo, que estava em perigo na Checoslováquia, já que o movimento em Praga foi considerado pelos soviéticos como "capitalista" e "contra-revolucionário"15. Do ponto de vista da política internacional, a aproximação entre Cuba e os soviéticos foi acompanhada de uma diminuição do estímulo aos grupos guerrilheiros latinoamericanos e de uma política externa mais moderada. Desde 1966, o governo cubano havia se afastado da política soviética ao promover a exportação da revolução, por meio do incentivo às guerrilhas na América Latina e em todo o "Terceiro Mundo"16.

Este distanciamento de Cuba dos soviéticos havia atingido seu ápice no início de 1968, quando Fidel Castro denunciou a União Soviética por diminuir o fornecimento do petróleo a ilha no ano anterior. A prisão de um grupo de dirigentes do antigo Partido Socialista Popular (PSP), denominação do Partido Comunista Cubano antes da Revolução, que foram acusados de formar uma "micro-fração", partidária de teses soviéticas e de "supostas atividades anti-governamentais", também havia sido um foco de tensão entre cubanos e soviéticos em janeiro de $1968{ }^{17}$. Neste processo da "micro-fração", Aníbal Escalante foi preso juntamente com 35 militantes, sendo que oito deles haviam pertencido ao PSP. Foram acusados de conspiração, de formar uma "micro-fração" dentro do Partido Comunista de Cuba (PCC), julgados e condenados a penas que variaram entre 3 e 15 anos de prisão. Para amenizar as tensões, o jornal Granma, órgão oficial do PCC, havia isentado a União Soviética de qualquer responsabilidade no caso. No entanto, somente a 
mudança na política internacional de Cuba representou uma reaproximação com a União Soviética.

Dentro de Cuba, este apoio representou um marco na "institucionalização" da Revolução Cubana e sua aproximação cada vez maior do modelo soviético. Iniciou-se em Cuba a "grande ofensiva revolucionária", que visava estimular a criação do "homem novo", estatizar massivamente o setor privado, por meio da centralização econômica, do esforço coletivo e do combate ao individualismo. Desde março de 1968, a "ofensiva revolucionária" nacionalizou milhares estabelecimentos comerciais e penalizou os serviços privados (trabalhadores por conta própria), o que gerou um problema de desabastecimento de alimentos e de ofertas de serviços ${ }^{18}$. Esta política foi aplicada até 1970 e favoreceu também a coletivização no campo, por meio da eliminação do mercado livre camponês e das parcelas familiares dentro das granjas estatais. Paralelamente, a União Soviética aumentou sua ajuda econômica à ilha, incluindo também um incremento no fornecimento de petróleo. A centralização econômica foi acompanhada de planos setoriais diretamente controlados por Fidel Castro. Estimulou-se muito o trabalho voluntário, houve uma ênfase no igualitarismo, com redução das diferenças salariais, substituição dos incentivos materiais pelos incentivos morais e uma expansão dos serviços sociais gratuitos, com o objeto de construir o "homem novo"19. Esta política econômica desenvolvia vários elementos do sistema orçamentário estatal, defendido por Che Guevara quando foi Ministro das Indústrias em Cuba, no início dos anos sessenta ${ }^{20}$.

O governo cubano propalava a "construção do comunismo" e defendia a propriedade coletiva dos bens de produção, além da distribuição igualitária e do desenvolvimento da consciência. Na visão do economista Carmelo Mesa-Lago, o processo cubano de "ofensiva revolucionária" teve certas semelhanças com alguns aspectos da Revolução Cultural Chinesa ${ }^{21}$. Do ponto de vista econômico, este processo na ilha culminou com a grande mobilização para impulsionar a safra de açúcar de 1970, cuja meta foi fixada pelo governo em 10 milhões de toneladas. Para atingir as estimativas da safra de 1970, houve uma enorme mobilização de trabalhadores para auxiliar na colheita da cana e uma diminuição de produtividade dos setores econômicos que não eram relacionados ao açúcar, além do deslocamento de parte dos trabalhadores para o campo, para o cumprimento da meta. $\mathrm{O}$ fracasso da safra de 1970, que atingiu uma produção récord de 8,5 milhões de toneladas de açúcar, levou o governo cubano a depender ainda mais da União Soviética, enquadrando-se no seu modelo de planificação e produção econômica.

Estas transformações no plano da política econômica também foram acompanhadas por mudanças na política cultural. Durante a "ofensiva revolucionária", algumas medidas de endurecimento no meio cultural foram 
tomadas pelo governo, como veremos a seguir no caso de algumas premiações polêmicas no campo literário. A prioridade eram os trabalhos "braçais" e os intelectuais teriam que ser "úteis" à Revolução, incorporando-se na "ofensiva revolucionária". No mês de outubro de 1968, os escritores Heberto Padilla e Antón Arrufat ganharam o IV Concurso Literário da Unión Nacional de Escritores y Artistas Cubanos (Uneac), com as obras Fuera del Juego (poesia) e Los siete contra Tebas (teatro), respectivamente. Apesar de premiadas por um júri composto de intelectuais cubanos e estrangeiros, as obras foram consideradas pela direção da Uneac como "politicamente conflituosas", já que eram "construídas sobre elementos ideológicos francamente opostos ao pensamento da Revolução" 22. As obras premiadas foram publicadas em novembro após reunião entre o comitê diretor da Uneac e os jurados do concurso. Elaborou-se a declaração da Uneac que acompanharia a publicação das duas obras e esclarecia sua discordância com o prêmio outorgado pelo júri:

el comité director de la Uneac hace constar por este medio su total desacuerdo con los premios concedidos a las obras de poesía y teatro que, con sus autores, han sido mencionados al comienzo de este escrito. La dirección de la Uneac no renuncia al derecho ni al deber de velar por el mantenimiento de los principios que informan nuestra Revolución, uno de los cuales es sin duda la defensa de ésta, así de los enemigos declarados y abiertos, como - y son los más peligrosos - de aquellos otros que utilizan medios más arteros y sutiles para actuar. (...) El respecto de la revolución cubana por la libertad de expresión, demostrable en los hechos, no puede ser puesto en duda. ${ }^{23}$

Los siete contra Tebas, de Antón Arrufat, baseava-se na obra de Ésquilo, para narrar as guerras fratricidas entre os irmãos Etéocles e Polinice, na cidade de Tebas, sitiada pelo inimigo estrangeiro. A peça recebeu a data de maio de 1968, o que significou uma maneira de Arrufat relacioná-la com a intensa movimentação social e política que acontecia neste período na França e ao redor do mundo. O prêmio de teatro do concurso da Uneac foi decidido pelos jurados Ricardo Salvat, Lito Gudkin, Juan Larco e os cubanos José Triana e Raquel Revuelta. Segundo constou também na publicação da obra, dois jurados, o peruano Juan Larco e Raquel Revuelta, votaram contra a premiação da obra: "Estamos por un teatro crítico, antidogmático, libre de prejuicios conservadores. Pero no podemos por eso dar nuestro voto por una obra que mantiene, a nuestro juicio, posiciones ambíguas frente a problemas fundamentales que atañen a la Revolución Cubana"24.

A direção da Uneac fez uma leitura da peça cuja referência seria a situação de Cuba, sitiada pelos Estados Unidos, em que o povo cubano estaria aterrorizado 
e angustiado diante da invasão dos imperialistas. Para a Uneac, a peça de Arrufat corroborava a visão dos "mercenários da Playa Girón”, que invadiram Cuba em 1961 e estavam convencidos de que a população estaria paralizada pelo terror, fato que não ocorreu ${ }^{25}$.

$\mathrm{Na}$ análise do crítico literário Jesús Barquet ${ }^{26}$, a declaração da Uneac interpretava de seu modo a peça, dirigia a leitura do público ao relacioná-la com o contexto cubano e advertia antecipadamente sobre seu caráter "contestatório". A Uneac, ao interpretar a luta fratricida, indicava aos leitores que Etéocles seria a representação de Fidel Castro e Polinice dos cubanos exilados. As "intrigas políticas" contra Arrufat de Raquel Revuelta e do seu irmão, o diretor Vicente Revuelta, serviram de catalizador no processo de censura contra a peça logo após sua premiação, contribuindo para o ostracismo da peça no meio cultural cubano. Entretanto, na análise de Jesús Barquet, Los siete contra Tebas é uma obra com conteúdo "subversivo" e "crítico-revolucionário". Entretanto, seu conteúdo "subversivo" foi rotulado pelos representantes oficiais da cultura como "diversionismo ideológico" e sua forma inusitada de tragédia grega transplantada a Cuba, em um momento que se esperava das obras um reflexo direto e ideológico do processo revolucionário, foi um grande desafio a política cultural oficial:

Los siete contra Tebas constituye un atrevido alegato en contra del poder divisionista, soberbio, demagógico y autoritario, y a favor de una utópica paz y armonía entre todos los conciudadanos. (...)Los siete contra Tebas de Arrufat haya sido en su momento (y aún lo siga siendo) un texto subrepticiamente subversivo debido a su mensaje crítico-revolucionario: una nueva revolución (esta vez no de violencia ni de heroismo épico, sino de paz, armonía, trabajo y reconciliación nacional) desde la entonces llamada revolución en el poder, es decir, en cresciente institucionalización a partir de 1959. ${ }^{27}$

A distribuição do livro editado, seu empréstimo nas bibliotecas e a encenação de Los siete contra Tebas foi proibida desde 1968 até o ano de 2001, quando foi novamente publicada na ilha ${ }^{28}$. Segundo depoimento de Antón Arrufat, ele nunca recebeu o prêmio de teatro da Uneac, que consistia em um diploma, uma viagem à Hungria e uma soma em dinheiro ${ }^{29}$. Esta peça representou para Arrufat sua exclusão das esferas culturais cubanas, uma vez que permaneceu sem publicar até 1980 e foi obrigado a trabalhar em uma pequena biblioteca municipa ${ }^{30}$. O silenciamento do escritor no final dos anos sessenta e setenta, contrastou com sua intensa atividade cultural e editorial no início da Revolução, seja no suplemento cultural Lunes de Revolución, ou na direção da revista Casa de las Américas, de 1960 a $1965^{31}$. Já no fim dos anos sessenta em Cuba afirmava-se uma forte censura política e ideológica que traria grandes limitações às criações no meio intelectual da ilha. 
O escritor Heberto Padilla ganhou o prêmio de poesia no mesmo Concurso da Uneac, com o textos de Fuera del Juego e recebeu a premiação com o voto unânime dos jurados J.M. Cohen, César Calvo, José Lezama Lima, José Z. Tallet e Manuel Díaz Martinez. Os jurados elaboraram a seguinte declaração sobre o livro premiado:

Fuera del Juego se sitúa del lado de la Revolución, se compromete con la Revolución y adopta la actitud que es esencial al poeta y al revolucionario; la del incoforme, la del que aspira a más porque su deseo lo lanza más allá de la realidad vigente. (...) La fuerza y lo que le da sentido revolucionario a este libro es, precisamente, el hecho de no ser apologético, sino crítico, polémico y estar esencialmente vinculado a la idea de la Revolución como la única solución posible para los problemas que obsesionan a su autor, que son los de la época que nos ha tocado vivir. ${ }^{32}$

Como Heberto Padilla acabara de estar envolvido, no fim de 1967 e início de 1968, em uma polêmica no suplemento cultural El Caimán Barbudo, sua premiação no Concurso desagradou amplos setores da direção da Uneac e do governo cubano. Os escritores Heberto Padilla e Lisandro Otero, este último vicepresidente do Consejo Nacional de Cultura, polemizaram em El Caimán Barbudo a respeito do prêmio Biblioteca Breve, recebido em 1967 por Guillermo Cabrera Infante, por seu romance Tres Tristes Tigres. Lisandro Otero também concorreu ao prêmio com o livro Pasión de Urbino. Padilla foi convidado pelos diretores de El Caimán Barbudo para escrever sobre o livro de Otero e além de criticá-lo duramente, defendeu a premiação do livro de Cabrera Infante, que na ocasião já se encontrava exilado em Londres. Apesar dos editores do suplemento publicarem um esclarecimento que sua posição era contrária àquelas emitidas por Padilla, o fato de terem publicado o artigo polêmico foi motivo de grande descontentamento na direção da União de Jovens Comunista (UJC), da qual o suplemento era o órgão cultural. A equipe editorial de El Caimán Barbudo foi substituída em janeiro de 1968, como fruto desta polêmica, além da própria remoção do escritor Jesús Díaz da direção do suplemento ${ }^{33}$.

Em sua autobiografia, La mala memória, Padilla explicou que Fuera del Juego foi elaborado em parte durante sua estadia a trabalho em Moscou, Budapeste, Praga e finalizado em Havana ${ }^{34}$. Como havia perdido seu emprego e encontrava-se marginalizado desde a polêmica em El Caimán Barbudo, Heberto Padilla narrou em suas memórias a delicada operação que realizou com a ajuda de sua esposa Belkis Cuzá Malé para inscrever seu livro no Concurso da Uneac. Belkis levou seu trabalho no último minuto antes do encerramento da inscrição e contaram também com o auxílio de um funcionário que era amigo deles na Uneac. Segundo versão 
de Padilla, quando a direção da Uneac descobriu sua inscrição, seu texto já havia sido enviado aos jurados, que não cederam às pressões para desclassificar seu livro do concurso. Apesar de haver obtido o prêmio por unanimidade, Padilla nunca recebeu a soma de dinheiro e a viagem à União Soviética que faziam parte da premiação ${ }^{35}$.

Fuera del Juego foi publicado, mas também foi precedido pela mesma declaração da Direção da Uneac, que acompanhou a polêmica peça de Antón Arrufat:

el autor mantiene dos actitudes básicas: una criticista y otra antihistórica. Su criticismo se ejerce desde un distanciamento que nos es el compromiso activo que caracteriza a los revolucionarios. Este criticismo se ejerce además prescindiendo de todo juicio de valor sobre los objetivos finales de la revolución y efectuando transposiciones de problemas que no encajan dentro de nuestra realidad. Su antihistoricismo se expresa por medio de la exaltación del individualismo frente a las demandas colectivas del pueblo en desarrollo histórico y manifestando su idea del tiempo como un círculo que se repite y no como un línea ascendente. Ambas actitudes han sido siempre típicas del pensamiento de derecha, y han servido tradicionalmente de instrumento de la contrarrevolución. ${ }^{36}$

Adireção da Uneac avaliou o livro de poemas de Padilla como "individualista" e expressão da "ideologia liberal burguesa". Padilla também foi acusado de "cético" e "reacionário", atitudes típicas dos intelectuais liberais dentro do capitalismo, além de não ter nenhuma "militância pessoal" e haver se ausentado nos momentos de dificuldade nos quais Cuba se enfrentou com o imperialismo. Fuera del Juego também foi mal visto pois sugeria "perseguições" e "climas repressivos" na ilha, e para a direção da Uneac a Revolução sempre se havia caracterizado por sua "abertura" e "generosidade". Além disso, os poemas demonstraram compaixão pelos "contra-revolucionários" que abandonaram o país e com aqueles que foram "fuzilados por seus crimes contra o povo", na visão da Uneac ${ }^{37}$.

Nesta declaração, a direção da Uneac passou a defender também a União Soviética, pois o livro de Padilla havia questionado o governo russo por suas numerosas prisões e pelo terror que se instalou no período dos "obscuros crimes de Stalin"38. Por fim, o prólogo elaborado pela direção da Uneac mencionou e criticou os artigos polêmicos de Padilla, publicados em El Caimán Barbudo, em que o escritor defendeu o escritor exilado Guillemo Cabrera Infante. Cabrera Infante acabara de declarar em entrevista a revista argentina Primera Plana, em julho de 1968, suas primeiras críticas públicas à Revolução, desde seu exílio ${ }^{39}$, o que comprometia ainda mais a situação de Padilla, já que Cabrera Infante foi considerado pela direção da Uneac "um traidor da Revolução". 
Tanto Los siete contra Tebas como Fuera del juego foram vistos pelos representantes do governo como "uma conspiração dos intelectuais contra a Revolução". No entanto, era o governo que estava restringindo a liberdade de criação, sobretudo porque nesta época chegavam em Cuba notícias de dissidências entre os intelectuais da União Soviética, Polônia e Checoslováquia, o que certamente desagradava os representantes do governo na ilha ${ }^{40}$. Algumas obras premiadas no concurso Casa de las Américas no ano de 1968 também foram alvos de muitos debates, como por exemplo, a peça Dos viejos pánicos, de Virgilio Piñera e o livro de contos Condenados de condado, de Norberto Fuentes. O júri de teatro do Concurso que concedeu o Prêmio a Piñera estava composto pelo diretor cubano Vicente Revuelta, o espanhol Max Aub, o uruguaio Hiber Conteris, o brasileiro José Celso Martinez Correa e o guatemalteco Manuel Galich. Segundo o crítico uruguaio, nesta peça Piñera refletia o processo revolucionário cubano por omissão e apresentava a "crítica de uma geração que não encontrava o modo de recuperar o sentido do histórico" ${ }^{41} \mathrm{O}$ dramaturgo Virgilio Piñera relatou o significado de sua obra:

En dos viejos pánicos yo me propuse otro problema existencial, como es el problema de vidas terminadas como son las de esos dos viejos, que ya no tienen nada que hacer frente a la sociedad... Se trata del miedo pánico (miedo total) de dos viejos. Tota y Tabo le tienen miedo a la vida. Es un miedo primigenio: no quieren comprometerse por miedo a las consecuencias de sus actos. Cuando se rehúsa asumir la vida y las consecuencias de vivirla, entonces sólo queda el juego..., jugar a que se vive. ${ }^{42}$

Alguns ensaios da peça Dos viejos pánicos foram realizados pelo grupo La rueda, dirigido por Humberto Arenal, que iria representá-la pouco depois da premiação. Entretanto, devido a inúmeros problemas, o grupo se dissolveu e a peça não chegou a ser encenada na época ${ }^{43}$. Apesar de certo incômodo causado pelo tema da peça, Dos viejos pánicos foi publicado em 1968 em Cuba, como parte da premiação e na Argentina ${ }^{44}$. Em 1969, a peça teve sua estréia mundial pelo grupo colombiano La Mama e posteriormente foi encenada também na Espanha franquista. Dos viejos pánicos somente foi representada em Cuba em 199045.

Já o prêmio de contos no Concurso Casa de las Américas em 1968 foi dado a Condenados de condado, de Norberto Fuentes, com a indicação da maioria do júri. Fizeram parte dos jurados os intelectuais Emilio Adolfo Westphalen, Claude Couffon, Jorge Edwards, Rodolfo Walsh e Federico Alvarez. A obra relatava por meio de contos a luta contra os grupos contra-revolucionários entre 1960 e 1966, nas montanhas de Escambray. O episódio ficou conhecido como "luta contra bandidos" e Norberto Fuentes havia presenciado o conflito fazendo a cobertura 
como jornalista. Na apresentação do livro, Fuentes esclareceu que a narrativa era fruto de sua imaginação, mas a obra gerou polêmicas em Cuba, colocando-o em dificuldades perante a polícia política e o exército ${ }^{46}$. Condenados de Condado foi considerada uma obra dissidente e por causa disto Fuentes perdeu seu trabalho e permaneceu durante quinze anos no ostracismo da vida cultural cubana ${ }^{47}$.

O escritor e diplomata chileno Jorge Edwards revelou como fez a defesa do prêmio ao livro de Norberto Fuentes no Concurso Casa de las Américas 1968 e que posteriormente, no mesmo ano, o livro foi atacado pela revista das Forças Armadas Verde Olivo, juntamente com outras obras, como mostrarei mais adiante:

Los cuentos de José Norberto Fuentes, que contribui a premiar en 1968, transcurren pues en estos parajes [Escambray], donde la huella de las balas da testimonio de la violencia y del dramatismo de la lucha. Pero Fuentes, que lo habia hecho como cronista, no quiso como narrador dividir el mundo en blanco y negro, con lo cual tocó el dogma de la inmaculada pureza del ejército revolucionario, de su disciplina, una de las divindades intocables en el altar de la Salud Pública. ${ }^{48}$

A resposta a estas premiações controversas veio em um encontro de escritores e artistas, realizado em outubro de 1968, em Cienfuegos, que tirou como resolução que os concursos da Uneac seriam formados a partir deste momento apenas por jurados cubanos, e que o concurso Casa de las Américas deveria convocar para o júri apenas intelectuais militantes, de preferência residentes em seus países, na América Latina e não na Europa, para evitar novas e maiores polêmicas ${ }^{49}$.

Ainda em 1968, como reação às obras polêmicas premiadas, uma forte campanha contra os escritores foi orquestrada a partir de artigos publicados na revista Verde Olivo, órgão das Fuerzas Armadas Revolucionarias, entre outubro e dezembro desse ano. Vários artigos de Verde Olivo foram assinados com o pseudônimo de Leopoldo Ávila, criticando as obras de Heberto Padilla e Antón Arrufat, além de outros escritores como Virgilio Piñera, Norberto Fuentes, José Rodríguez Feo, Guillermo Cabrera Infante e René Ariza. Para Pío Serrano, Leopoldo Ávila seria o pseudônimo do crítico literário José Antonio Portuondo, antigo militante do $\mathrm{PSP}^{50}$. Já na visão de Carlos Espinosa, Leopoldo Ávila seria o pseudônimo de Luis Pavon Tamayo, diretor do Consejo Nacional de Cultura ${ }^{51}$.

$\mathrm{O}$ artigo de Leopoldo Ávila intitulado "Las provocaciones de Padilla" comentou o primeiro livro de poesias publicado por Padilla em 1962, El justo tiempo humano, quando o escritor parecia despojar-se das atitudes do grupo do suplemento Lunes de Revolución e iniciar uma mudança revolucionária. Ávila frisou não só a vivência de Padilla nos Estados Unidos antes do triunfo da Revolução, como também suas inúmeras viagens e trabalhos fora de Cuba após 1959, em que "gastou alegremente dólares que lhe eram entregues para outra finalidade". 
No início dos anos sessenta, Padilla era um "jovem e prometedor poeta", que na visão de Leopoldo Ávila havia se transformado em uma "caricatura lamentável e clownesca". Os artigos de Padilla publicados em El Caimán Barbudo faziam a defesa de Guillermo Cabrera Infante como um "pretexto para atacar a Revolução", na visão de Ávila, e tratava-se de uma "luta pelo poder cultural"

Para Leopoldo Ávila, o julgamento do stalinismo que Padilla realizara deveria ser feito apenas pelos soviéticos e ele rechaçou que houvesse em Cuba qualquer manifestação deste fenômeno. Este artigo de Verde Olivo estendeu a crítica não só a Padilla, mas a outros intelectuais, que rodeavam escritores e editores estrangeiros que visitavam Cuba, para "aumentar artificialmente a sua fama" e conseguir alguma publicação internacional. O escritor Cezar López, jurado no concurso da Uneac, também foi explicitamente atacado, por conceder o prêmio ao poeta que era seu amigo. Padilla havia feito uma provocação ao enviar seu livro ao concurso da Uneac, uma vez que na concepção de Ávila, ele "desprezava e atacava a Revolução e o povo cubano". Leopoldo Ávila acusou Fuera del Juego de conter declarações "contra-revolucionárias" e de fazer o jogo do "imperialismo". Para Ávila, Padilla escreveu o livro para "fazer cartaz no exterior", satisfazer a sua "vaidade", por isso, passou sua imagem como "conflituoso" e "perseguido" Em sua visão, "se trata de alertar y alertarnos de cuanta basura contra el pueblo flota todavía en nuestro país" ${ }^{4}$, já que Fuera del Juego era um "panfleto contrarevolucionário" e por isto era necessário desmascará-lo:

Padilla ha preparado sus ataques contra la Revolución largamente. Ha desoído consejos y ha realizado actividades que van más allá de un poemita más o menos punzante, entrando en actividades delictivas. Busca desde hace meses una oportunidad, una provocación contra la Revolución para hacer de su caso un escandalo. Lo que no ha entrado en sus cálculos es que es contra nuestro pueblo contra quien se vira. En esta lucha contra el imperialismo, él ha preferido alinearse junto al enemigo del mundo. (...) Aunque él crea fuera del juego, las reglas del juego de la Revolución están dadas.... ${ }^{55}$

Já as críticas de Leopoldo Ávila a Antón Arrufat recaíram sobre sua “conduta imprópria" (homossexualidade) e que sua peça Los siete contra Tebas utilizava o tema de uma tragédia grega para mostrar uma tese "contra-revolucionária" Em Cuba, os escritores, artistas, e setores da juventude tinham uma intensa e efervescente vida cultural, muitas vezes homossexual, outras vezes de rebeldia juvenil, como ouvir o grupo de rock proibido Beetles ${ }^{57}$, ter cabelo comprido ou usar calças justas e com boca de sino, condutas consideradas "impróprias" para o puritanismo pregado como política oficial pelo governo ${ }^{58}$. As questões da contracultura e da revolução cultural tão em voga neste período, presentes nas 
reivindicações dos movimentos de contestação da juventude, como a liberação sexual, dos gays, dos negros e dos movimentos hippies não tiveram espaço para aberta reivindicação em Cuba.

Os artigos publicados por Ávila reorientavam a cultura cubana dentro da política de "ofensiva revolucionária" e mostraram os padrões permitidos na criação e crítica literária cubana, para Jesús Barquet ${ }^{59}$. Seus ataques aos escritores eram de ordem estética, moral e ideológica, já que Ávila criticou a despolitização das obras literárias e exigiu uma literatura militante, que refletisse os temas da Revolução. Nenhuma resposta foi publicada a estes artigos nas revistas cubanas, o que demonstrava o medo e a auto-censura que já imperavam no meio cultural. Os únicos questionamentos aos artigos de Verde Olivo foram publicados no jornal francês Le Monde e assinados por Saverio Cutino. Mariana Martins Villaça analisou em sua pesquisa como esta polêmica repercutiu dentro do Instituto Cubano del Arte e Industria Cinematográficos (Icaic). Três reuniões foram realizadas no Icaic, entre outubro de 1968 e janeiro de 1969, com a presença de cineastas e demais trabalhadores da instituição, quando na ocasião o diretor do Icaic Alfredo Guevara defendeu as posições da revista Verde Olivo e criticou duramente os escritores e intelectuais que não cumpriam seu papel na Revolução ${ }^{60}$. Este fechamento cultural tornou-se mais evidente a partir de 1971, com a prisão e autoconfissão de Padilla, episódio que ficou conhecido como "caso Padilla". Este caso marcou o fim da "lua de mel" entre o governo e a intelectualidade de esquerda internacional. Padilla ficou 28 dias preso e foi obrigado a fazer uma autocrítica para ser solto, em que confessou ter conspirado contra a Revolução, envolvendo sua esposa Belkis Cuzá Malé e os escritores Manuel Díaz Martínez, César López, Norberto Fuentes, Pablo Armando Fernández, Antón Arrufat, Lezama Lima e Virgilio Piñera. Sua autocrítica foi lida publicamente no salão de atos da Uneac, no dia 17 de abril de 1971, em sessão presidida por José Antonio Portuondo, quando Padilla viu-se obrigado a ampliar a sua confissão diante de muitos agentes de segurança do Estado, que filmaram o episódio $^{61}$. Padilla foi utilizado como bode expiatório pelo governo cubano para provar o alinhamento de Cuba com a política cultural soviética, além de abafar qualquer pretensão de uma política cultural mais aberta e eclética na ilha.

O caso ganhou repercussão internacional. A primeira carta de protesto dirigida a Fidel Castro contra a prisão de Padilla, assinada pelos escritores mexicanos do Pen Club do México, foi publicada em 2 de abril de 1971, no jornal Excelsior $^{62}$. Escritores de esquerda europeus e latino-americanos, simpatizantes da Revolução Cubana, assinaram outra carta enviada a Fidel Castro, publicada no jornal Le Monde, em 9 de abril de 1971, em que declararam seu desacordo em relação a prisão de Padilla e ao uso de "medidas repressivas" contra intelectuais que exerceram "o direito de crítica dentro da Revolução" 
Fidel Castro foi publicada em 21 de maio no jornal Madrid e também em Paris, em que sessenta intelectuais protestaram enfaticamente diante da confissão pública de Padilla, que se redimia de crimes políticos que tinham sido "forjados":

O conteúdo e a forma de dita confissão, com suas acusações absurdas e afirmações delirantes, assim como o ato celebrado na Uneac, na qual o próprio Padilla e os companheiros Belkis Cuzá, Díaz Martínez, César López e Pablo Armando Fernández se submeteram a uma penosa mascarada de autocrítica, recorda os momentos mais sórdidos da época stalinista, seus juízos pré-fabricados e suas caças as bruxas. (...) Exortamos evitar em Cuba o obscurantismo dogmático, a xenofobia cultural e o sistema repressivo que impulsionou o stalinismo nos países socialistas, e de que foram manifestações flagrantes sucessos similares aos que estão sucedendo em Cuba. (...) Quiséramos que a Revolução Cubana voltasse a ser o que em um momento nos fez considerá-la um modelo dentro do socialismo. ${ }^{64}$

A autoconfissão de Heberto Padilla ao invés de atenuar o escândalo internacional desencadeado com sua prisão, acabou por acentuar e abrir uma ruptura entre a política repressiva do governo cubano e a atitude dos intelectuais de várias partes do mundo, que até aquele momento, não acreditavam que o governo reproduzia em Cuba os métodos stalinistas ${ }^{65}$. Padilla ao ter se submetido às exigências da Seguridad del Estado e realizado a "farsa" de sua autocrítica, evidenciou o caráter autoritário do governo cubano. Sua confissão não foi sincera, mas produto da imposição dos órgãos de repressão do governo, pois continha muitas passagens com duplo sentido, que beiravam a "hipocrisia" ${ }^{6}$.

As restrições aos intelectuais em Cuba foram explicitadas, não só quanto à liberdade de criação e de expressão, mas também em relação ao controle de sua conduta pública e privada. $\mathrm{O}$ "caso Padilla" significou uma quebra de confiança entre grande parte dos escritores e artistas e o governo cubano. No plano internacional, o "caso Padilla" representou o fim da "lua-de-mel" entre os intelectuais de esquerda e a Revolução, já que muitos escritores e artistas retiraram definitivamente o seu apoio ao processo cubano.

Na seqüência, realizou-se o Primeiro Congresso Nacional de Educação e Cultura, entre 23 a 30 de abril de 1971. As resoluções deste Congresso intensificaram a repressão aos intelectuais homossexuais, impedindo-os de exercer qualquer função educacional ou cultural em $\mathrm{Cuba}^{67}$. No discurso de encerramento do Congresso, Fidel Castro definiu os padrões morais, ideológicos e sexuais que deveriam guiar os intelectuais e educadores. Suas obras "eram uma arma da Revolução" e seriam "úteis para o povo, para a libertação do homem”. Fidel também teceu críticas aos intelectuais estrangeiros que publicaram cartas na imprensa 
internacional, condenando o "caso Padilla". O endurecimento no meio cultural fez com que os anos setenta ficassem conhecidos como a "década gris da cultura cubana" ${ }^{\prime 68}$. O crítico literário Ambrosio Fornet, bastante afinado com a linha oficial governamental, reconheceu que 1971 representa o início do período conhecido como "quinquenio gris" ${ }^{69}$. As obras artísticas e literárias deveriam escolher temas épicos e triunfalistas, demonstrando uma orientação política rígida. Valorizavamse obras didáticas, que "refletissem o momento de construção do socialismo em Cuba". A crítica literária Mirta Aguirre defendeu o "realismo socialista cubano", que para ela, se aproximava dos cânones do modelo soviético. ${ }^{70} \mathrm{O}$ realismo socialista foi incentivado sobretudo pelos intelectuais que aderiram ao Partido Comunista Cubano, ou ainda por aqueles que já eram militantes comunistas antes do triunfo da Revolução.

A "parametrización de la cultura cubana" significou o estabelecimento de parâmetros ideológicos e morais que deveriam direcionar a conduta dos intelectuais. O diretor do Consejo Nacional de Cultura, Luis Pavón Tamayo, passou a impulsionar uma "campanha de saneamento", em que muitos intelectuais e artistas foram expulsos de seus postos de trabalho, acusados de terem "conduta imprópria." A partir deste momento, os intelectuais teriam que demonstrar "combatividade revolucionária", ou seja, participar como um militante das tarefas da Revolução ${ }^{71}$. Estas resoluções da política cultural adotadas a partir de 1971 confirmaram o fechamento no meio intelectual, que já havia sido iniciado no ano de 1968, marcando definitivamente o estabelecimento na ilha dos "anos de chumbo". Para a Revolução Cubana, o ano de 1968 representou um marco na passagem de uma Revolução mais independente para a entrada de Cuba na esfera de dependência do bloco soviético. Do ponto de vista da política cultural o ano de 1968 também foi um ponto de inflexão, que marcou o endurecimento da relação entre os intelectuais e o governo.

\section{NOTAS}

I FRANK, R. "Imaginaire populare et figures symboliques internationales: Castro, Hô, Mao et le Che." In: DREYFUS-ARMAND, G., FRANK, R., LÉVY, M-F., ZANCARINI-FOURNEL, M. (org.). Les années 68. Le temps de la contestation. Paris: Ed. Complexe/IHTP/CNRS, 2000, p. 31-47.

2 lbidem, idem p.36.

3 Do mesmo modo que a Revolução Cubana havia colocado em xeque o modelo soviético de socialismo e representava a esperança do triunfo da revolução na América Latina, o sucesso da revolução cultural chinesa, a partir de 1966, representou para os setores jovens uma resposta ao burocratismo de inspiração soviética. Ver: RIDENTI, M. Em busca do povo brasileiro. Artistas da revolução, do CPC à era da TV. Rio de Janeiro/São Paulo: Record, 2000, p.34.

4 BENEDETTI, M. (org.). Literatura y arte nuevo en Cuba. Barcelona: Ed. Laia, I977, p. 33- I 16.

5 VILLAÇA, M. M.. O Instituto Cubano del Arte e Industria Cinematográficos (Icaic) e a política cultural em 
Cuba (1959-1991). Tese de Doutorado, Faculdade de Filosofia, Letras e Ciências Humanas Universidade de São Paulo, v. I, São Paulo, 2006.

6 A declaração geral do Congresso Cultural de Havana foi aprovada por aclamação, com apenas três abstenções por escrito. A tradução é de minha autoria: "Nós, intelectuais procendentes de setenta países, reunidos no Congreso em Havana, proclamamos nossa solidariedade militante com todos os povos em luta e muito especialmente com o povo de Vietnã; nosso apoio irrestrito à luta dos negros e brancos progressistas norte-americanos; nossa decisão de participar, com todos os meios a nosso alcance, no combate do qual depende o futuro da humanidade. (...) Chamamos a denúncia e à investigação, à oposição cultural e a manifestação de protesto, a desmistificação das ideologias e ao manifesto, a resistência e ao fusil, e seguindo o exemplo heróico do Che, a luta armada e o risco de morrer se for necessário, para que uma vida nova e melhor seja possível.". Ver: MARTíNEZ PÉREZ, Liliana. Los hijos de saturno. Para una historia política y cultural de la intelectualidade cubana (1959-7I). México D. F.: Universidade Iberoamericana, 200 I. Tese de Doutorado (mimeo), p.350.

7 CASTRO apud VERDÈS-LEROUX, J. La lune et le caudillo. Le rêve des intellectuels et le régime cubain (1959-197/). Paris: Gallimard, 1989, p. 502.

8 A realização da OLAS, ocorrida de 31 de julho a 10 de agosto de 1967, foi presidida por Haydée Santamaría (diretora de Casa de las Américas) e contou com a participação de 27 delegações, apenas três de Partidos Comunistas (Uruguai, Costa Rica e El Salvador). O congresso fazia parte de uma estratégia do governo cubano para defender e apoiar movimentos de luta armada e grupos guerrilheiros no Terceiro Mundo, para promover revoluções que levariam esses países ao socialismo. A OLAS representava a tentativa de organizar uma Internacional no continente americano.

9 VILLAÇA, Op. Cit., p. I78- 179.

10 MOORE, C. Castro, the blacks and Africa. Los Angeles: Center for Afro-American Studies, University of California, I988, p. 308-310.

I I VILLAÇA, Op. Cit, , p. 180.

12 A simpatia da intelectualidade de esquerda em Relação à Revolução Cubana também estava presente no Brasil, não só porque representava uma alternativa ao modelo soviético, mas também porque passava uma imagem de abertura no campo cultural. $\bigcirc$ Prof. Luiz Alberto Moniz Bandeira escreveu um texto, em agosto de 1968, em que explicitava sua admiração, de como Fidel Castro havia permitido "a mais completa liberdade de criação artística e literária, no campo da revolução, admitindo o florescimento das mais diversas escolas". Ver: BANDEIRA, Luis Alberto Moniz. "O marxismo e a questão cultural." In: TROTSKI, L. Literatura e Revolução. Trad. e apresentação de Luiz Alberto Moniz Bandeira. Rio de Janeiro: Zahar, 1980, p. 17. Nos anos noventa, Moniz Bandeira elaborou uma análise crítica em relação ao processo revolucionário cubano. Ver: BANDEIRA, Luiz Alberto Moniz. De Martí a Fidel. A Revolução Cubana e a América Latina. Rio de Janeiro: Civilização Brasileira, 1998.

I3 SERRANO, Pío E. "Álbum familiar (sin ira)". In: VÁZQUEZ DÍAZ, René (org.). Cuba: voces para cerrar un siglo (II). Estocolmo: The Olof Palme International Center, 1999, p. I08- 109.

I 4 FORNÉS-BONAVÍA DOLZ, L. Cuba cronología. Cinco siglos de historia, política y cultura. Madri: Ed. Verbum, 2003, p.242.

15 Ibidem, idem, p. 242.

I6 Denise Rollemberg mostrou em sua pesquisa o treinamento de guerrilheiros brasileiros em Cuba e como houve uma redução significativa dos treinamentos e da exportação da Revolução a partir de 1968. Ver: ROLLEMBERG, D. O apoio de Cuba à Luta armada no Brasil. O treinamento guerrilheiro. Rio de Janeiro: Mauad, 200I, p. 18.

17 MESA-LAGO, C. Dialéctica de la Revolución Cubana: del idealismo carismático al pragmatismo institucionalista. Madri: Ed. Playor, 1979, p. 31; FORNÉS-BONAVÍA DOLZ, Op. Cit., p. 24l.

I 8 FORNÉS-BONAVÍA DOLZ, Op. Cit., p.24I.

19 MESA-LAGO, C. Economía y bienestar social en Cuba a comienzos del siglo XXI. Madri: Ed. Colibrí, 2003, p.24.

20 Che travou na época um debate econômico com Carlos Rafael Rodríguez, presidente do Instituto Nacional de Reforma Agrária (INRA), defensor da reforma econômica, em voga em meados dos anos 
sessenta na União Soviética. Ver: PERICÁS, Luis Bernardo. Che Guevara e o debate econômico em Cuba. São Paulo: Xamã, 2004.

21 MESA-LAGO, C. Dialéctica de la Revolución Cubana, Op. Cit, p. 21.

22 "Declaración de la Uneac". In: ARRUFAT, Antón. Los siete contra Tebas. Havana: Ed. Unión, 1968, p.

7-9.

23 Ibidem, idem, p. 7-9.

24 "Voto particular de los jurados Revuelta y Larco". In: ARRUFAT, Op. Cit, p. 19.

25 "Declaración de la Uneac", Op. Cit. p. 14.

26 BARQUET, J. Teatro y revolución cubana - Subversión y utopía en Los siete contra Tebas de Antón Arrufat. Lewiston/Queenston/Lampeter: The Edwin Mellen Press, 2002, p. 59.

27 Ibidem, idem p. 23.

28 Ibidem, idem p. 15.

29 ARRUFAT, A. apud BARQUET, Op. Cit., p. 141.

30 BARQUET, Op. Cit , p. 18.

3। A destituição de Antón Arrufat da direção da revista Casa de las Américas relacionou-se com a presença de Allen Ginsberg em Cuba, já que foi divulgado que ele havia feito o convite para a vinda do poeta homossexual à ilha para participar do jurado do concurso Casa de las Américas em 1965, além de ter publicado na revista um poema de temática homossexual de José Triana, enquanto dirigia Casa de las Américas. Ver: BARQUET, Op. Cit. p.25. Sobre sua participação em Lunes de Revolución ver: MISKULIN, S. C. Cultura ilhada. Imprensa e Revolução Cubana (1959-196I). São Paulo, Xamã/FAPESP, 2003. Sobre a revista Casa de las Américas ver: MOREJÓN ARNAIZ, Idalia. Política e polêmica na América Latina: Casa de las Américas e Mundo Nuevo. Tese de Doutorado, PROLAM Universidade de São Paulo, São Paulo, 2004; QUINTERO HERENCIA, J. C. Fulguración del espacio. Letras e imaginario institucional de la Revolución Cubana (1960-197I). Rosario: Beatriz Viterbo, 2002.

32 “Dictamen del jurado del Concurso de la Uneac 1968." In: PADILLA, Heberto. Fuera del juego. Miami: Ediciones Universal, 1998, p.87-88.

33 Sobre as polêmicas publicadas nos anos sessenta em El Caimán Barbudo e o fim da primeira época do suplemento ver: MISKULIN, S. C. Os intelectuais cubanos e a política cultural da Revolução (1961 - 1975). Tese de Doutorado Universidade, Faculdade de Filosofia, Letras e Ciências Humanas de São Paulo, São Paulo, 2005.

34 PADILLA, H. La mala memoria. Barcelona: Plaza \& Janes, 1989, p. 128.

35 Ibidem, idem p. 147.

36 "Declaración de la Uneac". In: PADILLA, H. Fuera del juego, Op. Cit., p. I I6- 1 I 7.

37 Ibidem, idem p. I 17- I 18.

38 lbidem, idem p. $119-120$.

39 CABRERA INFANTE, G. Mea Cuba. Trad. de Josely Vianna Baptista. São Paulo: Companhia das Letras, 1996. p.26-34.

40 DÍAZ MARTÍNEZ, M apud BARQUET, J. "Subversión desde el discurso no-verbal y verbal de Los siete contra Tebas de Antón Arrufat”. Latin American Theatre Review, n.2, vol. 32, 1999, p.30.

4I CONTERIS, Hiber apud ESPINOSA DOMÍNGUEZ, Carlos. "Una dramaturgia escindida. Cronología." In: ESPINOSA DOMÍNGUEZ, Carlos (org.). Teatro cubano contemporáneo. Antología. Madri: Fundo de Cultura Economica, 1992, p. 39.

42 PIÑERA apud ESPINOSA DOMÍNGUEZ, Op. Cit., p. 198.

43 ESPINOSA DOMÍNGUEZ, Op. Cit., p. 201.

44 BARRETO, T. C. A libélula, a pitonisa. Revolução, homossexualismo e literatura em Virgilio Piñera. São Paulo: Iluminuras/ Fapesp, 1996, p. I58.

45 ESPINOSA DOMÍNGUEZ, C. Op. Cit., p.39.

46 FUENTES, N. Condenados de Condado. Havana: Casa de las Américas, 1968, p.8.

47 FUENTES, N. Dulces guerreros cubanos. Barcelona: Seix Barral, 1999.

48 EDWARDS, J. Persona non grata. Barcelona: Tusquets Editores, I99।, p. 155. 
49 BARRETO, T. C. Op. Cit., p. 159.

50 SERRANO, P. E. "Quatro décadas de políticas culturales." Revista Hispano-Cubana, Madri, n.4, maiosetembro de 1999, p. 46.

5I ESPINOSA DOMÍNGUEZ, Op. Cit., p. 43.

52 ÁVILA, L. "Las provocaciones de Padilla." Verde Olivo, ano IX, n. 45, 10 de novembro de 1968, p. I718. In: PADILLA, H. Fuera del juego, Op. Cit., p. I I I.

53 Ibidem, idem, p. I I3-1 I4.

54 Ibidem, idem p. 113.

55 Ibidem, idem p. I I3- I I 4.

56 ÁVILA, L. apud BARQUET, Op. Cit, p. 17-18.

57 Um dos motivos do governo para a censura da execução em Cuba dos Beatles baseava-se no perigo de disseminação de símbolos, valores e comportamentos "yanquis" entre os jovens. Mariana Martins Villaça mostrou em sua pesquisa como o cantor e compositor Silvio Rodríguez foi vetado na rádio e teve suspenso seu programa de TV Mientras Tanto, após declarar em janeiro de 1968 que suas canções eram devedoras da música dos Beatles e que os considerava a vanguarda musical no mundo. Ver: VILLAÇA Polifonia Tropical. Experimentalismo e engajamento na música popular (Brasil e Cuba, 1967-1972). São Paulo, Humanitas, Série Teses / História Social USP, 2004, p. I 13.

58 O documentário Conducta Impropia e a autobiografia de Reinaldo Arenas mostraram a intensidade da rebeldia cultural e do mundo gay cubano nos anos sessenta e as inúmeras tentativas do governo cubano de reprimir os homossexuais, através de prisões e dos campos de trabalhos forçados para reabilitação, conhecidos como Umaps, Unidades Militares de Apoio à Produção. Ver: ALMENDROS, N; JIMENEZLEAL, O. Conducta Impropia. Madri: Playor, 1984; ARENAS, R. Antes que anoiteça. Trad. Irène Cubrie. Rio de Janeiro: Record, 1995; BEJEL, E. Gay Cuban Nation. Chicago/Londres: The University of Chicago Press, 2001 ; QUIROGA, J. Tropics of desire Interventions from Queer Latino America. Nova York/ Londres: New York University Press, 2000.

59 BARQUET, Op. Cit., p. 16.

60 VILLAÇA, M. M. O Instituto Cubano del Arte e Industria Cinematográficos (Icaic) e a política cultural em Cuba (1959-1991). Tese de Doutorado, Faculdade de Filosofia, Letras e Ciências Humanas, v. I, Universidade de São Paulo, São Paulo, 2006, p. I84-186.

6I EDWARDS, Op. Cit.; BARRETO, T. C.; GIANERA, P.; SAMOILOVICH, D. "Virgilio Piñera. Cronologia." Trad. de Teresa Cristófani Barreto. In: Revista Usp, n.45. São Paulo, mar/mai 2000; PADILLA, H. Fuera del juego, Op. Cit..

62 Os intelectuais mexicanos Carlos Fuentes, Octavio Paz e Juan Rulfo, entre outros, assinaram esta carta. Ver: "Carta del Pen Club de México a Fidel Castro". Excelsior, México, 2 de abril de 197I. In: PADILLA, H. Fuera del juego, Op. Cit., , p. 122.

63 A carta, conhecida como Declaración de los 54, foi assinada por Jean-Paul Sartre, Simone de Beauvoir, Italo Calvino, Marguerite Duras, Carlos Franqui, Juan Goytisolo, Alberto Moravia, Octavio Paz, Hans Magnus Enzensberger, Julio Cortázar, Carlos Fuentes, Gabriel García Márquez, Mario Vargas Llosa, Jorge Semprún, Carlos Barral, Maurice Nadeau, Rossana Rossanda, entre outros. Ver: "Primera carta de los intelectuales europeos y latinoamericanos a Fidel Castro." Le Monde, Paris, 9 de abril de 197I. In: PADILLA, Heberto. Fuera del juego, Op. Cit., p. 123.

64 Assinaram esta carta, a Declaración de los 62, Nathalie Sarroute, Susan Sontag, Pier Paolo Pasolini, Alain Resnais, André Gorz, Rodolfo Hinostroza, Juan Rulfo, José Agustín Goytisolo, entre outros, além da maioria dos intelectuais que subscreverem a carta anterior, publicada no Le Monde. Ver: "Segunda carta de los intelectuales europeos y latinoamericanos a Fidel Castro". Madrid, 2 I de maio de 197I. In: PADILLA, H. Fuera del juego, Op. Cit., p. |60-161. A tradução é de minha autoria.

65 Stálin comandou uma campanha ostensiva contra os dirigentes do bureau político da época de Lênin. Bukharin, Zinoviev, Kamenev, Rykov, Radek, entre outros, foram afastados da direção, presos e mortos. ○́pice dos expurgos e das autoconfissões ocorreram durante os Processos de Moscou, entre 1936 e 1938, quando cinco milhões de soviéticos foram condenados à prisão, à morte, ou aos campos de trabalhos forçados. Ver: TROTSKI, Leon. La revolución traicionada. Que és y a donde va la Unión Soviética. 
Barcelona: Fontamara, 1977; FERRO, M. O Ocidente diante da Revolução Soviética. A História e seus mitos. Trad. de Carlos Nelson Coutinho. São Paulo: Brasiliense, 1984.

66 Para Juan Goytisolo, a confissão de Padilla era "caricaturesca" e seu tom era "burlesco", ou seja, tratavase de uma mensagem codificada, que deveria ser interpretada, com leitura nas entrelinhas. Padilla havia feito suas "auto-inculpações abjetas", exagerando ao absurdo as fórmulas e os clichês, com um aparente "servilismo sem limites", que escondiam a farsa que ele foi obrigado a representar. Ver: GOYTISOLO, Juan apud LEANTE, C. Revive, historia. Anatomía del castrismo. Madri: Biblioteca Nueva, 1999, p. 220-221. Na interpretação de Roger Reed, a autocrítica de Padilla utilizou uma "linguagem dupla" e foi pronunciada para ser entendida de duas maneiras. Padilla queria transmitir que sua autoconfissão não era sincera e que havia sido forçado a fazer aquela declaração, segundo Reed. Ao declarar desde o princípio que seu discurso não era imposto pela Revolução, Padilla queria manifestar exatamente o contrário e que toda sua fala seria "pura hipocrisia". Ver: REED, R. apud LEANTE, C. Op. Cit., p. 2।3. Já na reedição de seu livro Fuera del Juego, em 1998, Padilla avaliou que sua confissão havia sido uma "burla", pois repetiu de memória um texto previamente redigido na prisão pelos órgãos da Seguridad del Estado. Ver: PADILLA, Heberto. Fuera del juego, Op. Cit., p. 9.

67 Resoluções do Primeiro Congresso Nacional de Educação e Cultura, São Paulo, Livramento, 1980, p. 29.

68 CANCIO ISLA, W, apud, BARQUET, J. J. "El teatro cubano en la encrucijada sociopolítica (19591990)". In: La Palabra y el hombre, México, n. I08, out-dez. 1998, p. 72.

69 FORNET, Ambrosio apud ESPINOSA, Carlos. "Uma dramaturgia escindida. Cronología." In: Teatro cubano contemporáneo. Antología. Madri, Fundo de Cultura Economica, 1992, p. 103.

70 AGUIRRE, M. "Realismo, realismo socialista y la posición cubana." In: Estética selección de lecturas. Havana, Editorial Pueblo y Educación, 1987. O realismo socialista, política cultural implementada por Jdanov na União Soviética nos anos 30 e 40, buscou enquadrar as produções intelectuais dentro de normas patrióticas, otimistas, populares, com uma linguagem que fosse acessível ao povo. Conforme analisou criticamente Boris Schnaiderman, o realismo socialista foi definido como "a representação verídica da realidade em seu desenvolvimento." Ver: SCHNAIDERMAN, B. Os escombros e o mito. A cultura e o fim da União Soviética. São Paulo, Companhia das Letras, 1997, p. 176.

7I BARQUET, J. "El teatro cubano en la encrucijada sociopolítica (I959- 1990)", Op. Cit., p. 7I. 